\title{
Dampak Kurangnya Informasi mengenai Kondisi Runway setelah Hujan terhadap Keselamatan Penerbangan
}

\section{The Impact of Lack of Information regarding Runway Conditions after The Rain to Flight Safety}

\author{
Dhian Supardam ${ }^{1}$, Rachma Fitrianti ${ }^{2}$, Sukma Nur Yulia ${ }^{3}$ \\ dhians14.dd@gmail.com, rachma.atc12@gmail.com, sukma_ny@gmail.com
}

Politeknik Penerbangan Makassar

\begin{abstract}
ABSTRAK
Dalam dunia penerbangan banyak aspek yang mendukung untuk terjadinya suatu penerbangan yang aman dan lancar hingga dapat menghubungkan perjalanan antar pulau bahkan benua. Jika berbicara mengenai penerbangan pasti yang terlintas adalah peswat yang mengudara secara teratur di udara, namun untuk mengudaranya pesawat tersebut secara teratur perlu seorang pemandu yang memastikan kegiatan penerbangan dalam keadaan lancar dan aman. Pemandu lalu lintas udara atau air traffic controller (ATC) ialah seorang yang memastikan dan memandu pesawat saat berada di daratan maupun saat mengudara, ATC bertugas memberikan informasi yang dibutuhkan pilot, seperti informasi cuaca, navigasi penerbangan, dan lalu lintas udara. Ia juga bertugas memandu pilot untuk menaikan, menurunkan, atau membelokkan pesawat. ATC harus siap memandu pesawat dalam cuaca panas ataupun hujan sekalipun. Keadaaan cuaca dan hujan dapat sangat berpengaruh terhadap kegiatan penerbanngan. Hal ini desebabkan dari runway yang merupakan hal utama dalam suatu bandar udara. Runway tersebut digunakan untuk kegiatan take off dan landingnya pesawat. Jika hujan terjadi maka kondisi runway akan basah dan saat runway basah sangat berisiko terhadap kegiatan pesawat apalagi jika terdapat genangan air yang berada di runway. Hal tersebut dapat mengakibatkan terjadinya musibah tergelincir, maka untuk mencegah terjadinya hal tersebut perlu adanya alat standing water detector yang saat ini belum tersedia di bandar udara El Tari, Kupang. Alat tersebut digunakan untuk memberikan informasi mengenai ketinggian air di runway.
\end{abstract}

Kata kunci: runway; hujan; genangan air

\section{ABSTRACT}

In the world of aviation, there are many aspects that support the occurrence of a safe and smooth flight to be able to connect trips between islands and even continents. When talking about flight, of course, what comes to our mind is a plane that airs regularly in the air, but to pass it through it regularly requires a guide which ensures flight activities in a smooth and safe condition. An air traffic controller or air traffic controller (ATC) is a person who ensures and guides the aircraft while it is on the ground or it is in the airborne, the ATC is also tasked with providing information needed by the pilot, such as weather information, flight navigation, and air traffic. And guide the pilot to raise, lower, or turn the plane. ATC must be ready to guide the aircraft even in hot or rainy weather. Rainy weather conditions can greatly affect flight activities, this is caused by runways that are the main thing in an airport. The runway is used for taking off and landing an aircraft. If it rains, the runway conditions will be wet and when the runway is wet, there is a high risk of aircraft activities, especially if there is standing water on the runway. which is currently not available at El Tari airport, Kupang. The tool is used to provide information about water 
levels on the runway.

Keywords: runway; rain; standing water

\section{PENDAHULUAN}

Saat ini pergerakan lalu lintas di Bandar Udara Internasional El Tari Kupang semakin meningkat. Oleh Karena itu, kualitas pelayanan dalam hal pemanduan lalu lintas udara perlu ditingkatkan lagi. Maka dari itu di Bandar Udara Internasional El Tari Kupang pada Unit Aerodrome Control Tower, ditemukan beberapa kendala dalam pemberian pelayanan lalu lintas udara, hal ini menyebabkan pelayanan jadi kurang maksimal. Kendala yang dirasakan ialah Bandar Udara Kupang adalah kekurangan pemberian informasi mengenai kondisi runway setelah hujan untuk menjamin keselamatan pesawat yang akan menggunakan runway tidak tersampaikan secara akurat, jika informasi yang didapatkan oleh air traffic controller kurang lengkap maka kinerja pemberian informasi untuk pesawat kurang maksimal.

Pada Bandar Udara El Tari Kupang terdapat aktivitas pengecekan runway terjadwal namun belum terdapat informasi yang pasti mengenai kondisi runway pasca hujan, apakah runway tersebut tergenang $3 \mathrm{~mm}$ atau tidak. Dalam dunia penerbangan informasi adalah hal yang terpenting pada pemberian pelayanan lalu lintas udara. Pada wilayah Nusa Tengga Timur tak dapat diprediksi, pada saat musim kemarau cuaca dapat sangat panas dan saat memasuki musim penghujan, hujan dapat turun secara terus menerus disertai angin kencang. Kondisi hujan dapat berpengaruh pada runway.

Saat kondisi hujan kewaspadaan lebih ditingkatkan lagi dikarenakan kondisi runway yang basah dan dapat berakibat terjadi runway excursion seperti pesawat yang tergilincir. Pengertian runway excursion sendiri adalah suatu kejadian dimana suatu pesawat mengalami peristiwa keluar landas pacu baik diakhir ujung landas pacu (overrun) ataupun disisi kiri maupun sisi kanan landasan pacu (veer off) yang terjadi pada saat pesawat akan tinggal landas (take off) maupun pada saat melakukan pendaratan (landing).

Saat keadaan cuaca yang disertai hujan akan mengakibatkan kondisi runway yang basah atau runway wet maka informasi runway sangat dibutuhkan, untuk menunjang pemberian informasi yang paling terkini mengenai kondisi runway oleh Air Traffic Controller.

Masalah yang menjadi perhatian utama yakni:

a. Sesuai dengan Doc. 4444 mengenai kentinggian air di runway. Kondisi ini yang membuat pilot meningkatkan kewaspadaan akan terjadinya runway excursion. Ketinggian air yang tergenang ataupun standing water yang maksimal adalah setinggi 3 .

b. Mengenai penanganan bandara pada Annex 14 (Aerodrome).

c. Memberikan pelayanan lalu lintas udarasa sesuai dengan 5 Objective of Air Traffic Controller pada Annex 11 (Air Traffic Service)

d. Pemberian keterangan mengenai ketinggian air sangat diperlukan, untuk menghasilkan data tersebut guna meningkatkan keamanan kegiatan penerbangan di Bandar Udara Internasional El Tari Kupang dan sampai saat ini belum tersedianya informasi tersebut.

Runway merupakan suatu objek paling penting disuatu bandar udara. Hal demikian disebabkan kegiatan utama pesawat yakni mendarat dan lepas landas seluruhnya berada pada runway. Sabur (2018) menyatakan beberapa komponen pada Runway diperlukan untuk mengakomodasi kebutuhan proses operasional pesawat terbang secara aman. Maka dari itu kondisi runway sangatlah berpengaruh pada keselamatan penerbangan. Pihak terkait harus memastikan jika runway itu sudah bersih dari segala gangguan. Salah satu hal yang patut diwaspadai yang dapat membawa pengaruh besar pada keselamatan penerbangan adalah kondisi runway yang basah akibat hujan.

Runway yang basah dapat meingkatkan pesawat mengalami insiden yang tidak diinginkan, apalagi jika terdapat standing water pada runway tersebut. Standing water merupakan suatu kondisi dimana runway terdapat genangan air. Dengan begitu perlu diketahui batas maksimum amannya pesawat 
melakukan aktivitas penerbangan di suatu bandar udara dengan kondisi runway yang basah. Maka dari itu perlu penanganan agar standing water tidak menimbulkan dampak yang besar bagi aktivitas penerbangan.

\section{METODE}

Dalam pengumpulan data dalam laporan penelitian ini berdasarkan hasil tanya jawab antar pihak terkait pada tempat On the Job Training penulis. Penelitian ini menggunakan metode kualitatif deskriptif berdasarkan data primer serta data sekunder yang tersedia.

\section{HASIL DAN PEMBAHASAN}

Pemberian keterangan mengenai ketinggian air sangat diperlukan, apalagi saat kondisi setelah hujan (Idyaningsih, 2018). Untuk menghasilkan data tersebut guna meningkatkan keamanan kegiatan penerbangan di Bandar Udara Internasional El Tari Kupang dan sampai saat ini belum tersedianya informasi tersebut. Informasi bahwa landasan pacu atau bagiannya mungkin licin saat basah harus tersedia. Penentuan bahwa landasan pacu atau bagiannya mungkin licin saat basah tidak semata-mata didasarkan pada pengukuran gesekan yang diperoleh dengan menggunakan alat pengukur gesekan kontinu. Namun dalam pemberian informasi yang mengenai kondisi setelah hujan di runway apakah bebas dari genangan air atau semacamnya, Air Traffic Controller kupang belum dapat memberikan informasi yang akurat dikarenakan belum tersedianya informasi tersebut.

Dalam menanggulangi tersedianya informasi mengenai kondisi runway setelah hujan itu dapat didapatkan dengan penambahan alat pengukur standing water atau disebut standing water detector (Sabur, 2018). Alat tersebut sangat berguna bagi air traffic controller guna menunjang pemberian informasi kepada pilot sehingga dapat menghindari terjadinya runway excursion, dengan adanya standing water detector dengan cara kerja yakni mengirimkan signal ketinggian genangan air, sehingga $A T C$ dapat meneruskan informasi tersebut kepada pilot. Selain itu dapat juga dilakukan pengecekan manual yang dilakukan oleh pihak landasan dan melihat apakah kondisi runway dan memastikan air yang terdapat di runway tidak melebihi $3 \mathrm{~mm}$. Maka dapat diketahui di Bandar Udara Internasional El Tari Kupang,

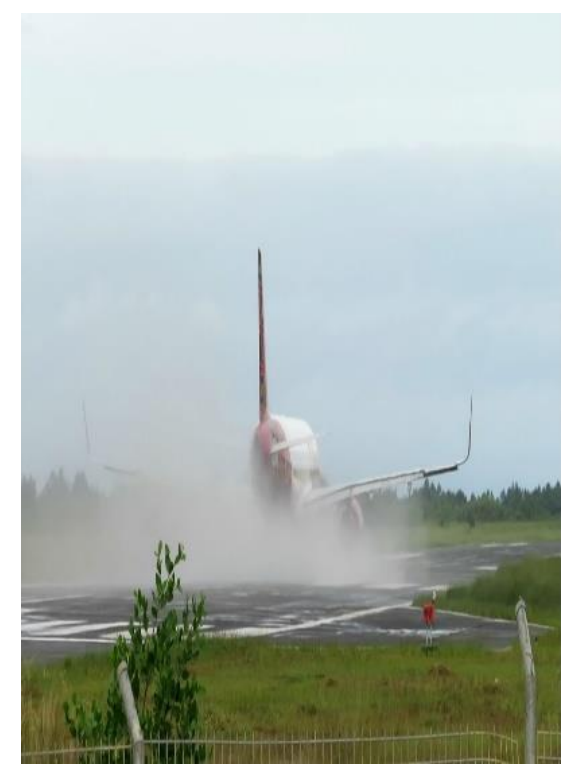

Gambar 1. Kondisi runway basah

a. Saat ini menara pemantau lalu lintas udara memiliki bebarapa alat penunjang pemberian informasi namun alangkah lebih baik lagi jika informasi mengenai ketinggian genangan dapat direalisasikan guna menunjang kinerja $A T C$ di Bandar Udara El Tari Kupang.

b. Penambahan alat pengukur standing water atau disebut standing water detector. Alat tersebut sangat berguna bagi air traffic controller untuk menunjang pemberian informasi kepada pilot.

c. Melakukan pengecekan manual yang dilakukan oleh pihak landasan dan melihat apakah kondisi runway dalam keadaan baik dan memastikan air yang terdapat di runway tidak melebihi $3 \mathrm{~mm}$.

Dalam hal koordinasi untuk menyampaikan kondisi runway selatah hujan dapat ditingkatkan lagi dengan adanya LOCA (Local of Coordination Agreement) mengenai pemberian informasi aktual setelah hujan di Runway (Irfan, 2019). Hal ini berguna agar pihak pihak terkait ikut andil dalam meningkatkan pelayanan pernerbangan 


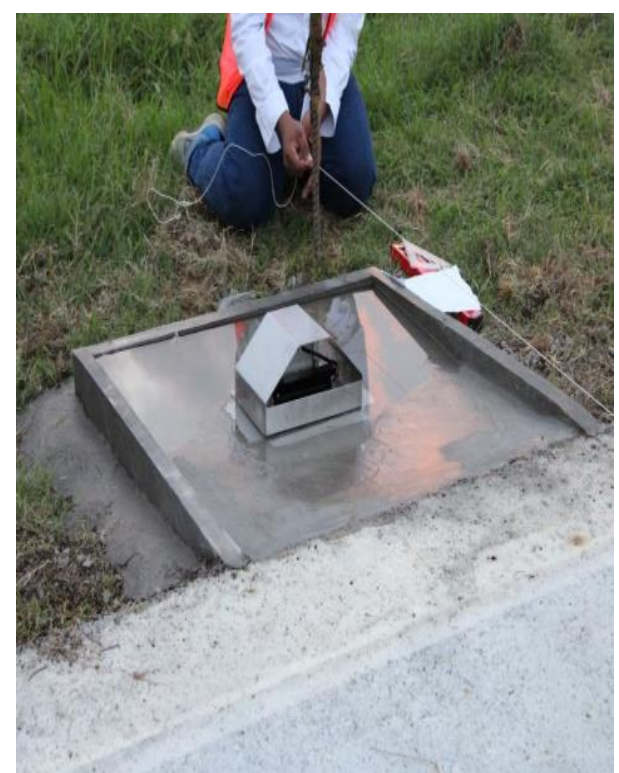

Gambar 2. Alat Standing Water

\section{KESIMPULAN}

Hasil pengamatan yang dilakukan penulis selama melaksanakan On the Job Berdasarkan Training dapat disimpulkan bahwa Bandar Udara Internasional El Tari Kupang dapat memberikan pelayanan yang lebih baik lagi sesuai dengan berdasar pada 5 Objective of Air Traffic Controller pada Annex 11 (Air Traffic Service), jika terdapat detector standing water yang dapat membantu ATC dalam memberikan informasi terkini mengenai kondisi runway yang lebih akurat sehingga informasi yag akan diberikan ke pilot akan lebih terjamin. Karena hal ini untuk menunjang terwujudnya keselamatan dan keamanan dalam pemberian pelayanan dan pengaturan lalu lintas udara. Serta untuk menjamin terciptanya keselamatan, efisiensi, dan keteraturan, dan ditunjang dengan fasilitas yang dapat menunjang ATC dalam menjaga efisiensi lalu lintas udara.

\section{Ucapan Terima Kasih}

Terima kasih diucapkan kepada Direktur Politeknik Penerbangan Makassar, kepada General Managaer Perum LPPNPI cabang Kupang beserta jajarannya serta senior ATC dan pihak terkait yang telah mendukung telaksananya On The Job Training ini sehingga penulis mendapatkan pengalaman secara langsung di Lapangan sebagai syarat selesainya kegiatan On The Job Training. Tidak lupa penulis haturkan terima kasih kepada Pusat Penelitian dan Pengabdian Masyarakat yang telah memotivasi kami untuk publikasi karya ilmiah.

\section{DAFTAR PUSTAKA}

Idyaningsih, N. (2018). Overview of Occupancy Time Landing Runway to Taxiway Configuration in Haluoleo Kendari Airport. Airman: Jurnal Teknik Dan Keselamatan Transportasi, 1(2), 37-45. https://doi.org/10.46509/ajtk.v1i2.64 .

International Civil Aviation Organization, Annex 14 Aerodrome.

International Civil Aviation Organization. (2001). Annex 11 Air Traffic Services thirteenth edition, Canada.

International Civil Aviation Organization. (2007). Doc 4444-ATM/501 fifthteenth edition.

Irfan. (2019). Improvement of Safety in the Domine Eduard Airport Domestic Eduard Airport in Sorong. Airman: Jurnal Teknik Dan Keselamatan Transportasi, 2(2), 168-185. https://doi.org/10.46509/ajtk.v2i2.117

Pedoman Pelaksanaan On The Job Training program studi Pemandu lalu lintas udara.

Republik Indonesia. (2003). Aeronatical Information (AIP) Supplement Bandar Udara Internasional El Tari Kupang, Directorat General of Air Communication, Jakarta.

Republik Indonesia. (2010). Aeronatical Information (AIP) Supplement Volume III Bandar Udara Internasional El Tari Kupang, Directorat General of Air Communication. Jakarta.

Republik Indonesia. (2013). Aeronatical Information (AIP) Supplement Bandar Udara Internasional El Tari, Directorat General of Air Communication. Jakarta.

Sabur, F. (2018). Effect of Runway Position 
13/31 and 03/21 Against Ground Control Unit Services in the International Airport of Sultan Hasanuddin Makassar. Airman: Jurnal Teknik Dan Keselamatan Transportasi, 1(2), 1-11. https://doi.org/10.46509/ajtk.v1i2.53 